\title{
A Medium is a Medium is a Medium is a Medium
}

Solveig Daugaard

At the symposium Media Archaeology and Artistic Practice held at Datamuseet in Linköping, September 17th 2015, a discussion was raised by invited keynote speaker Garnet Hertz, artist and associate professor at Emily Carr University, concerning the discourse around the concept of a media archaeological lab: Was this perhaps mainly a question of strategic naming? Can the desire to construct labs instead of other, more traditional, humanist and artistic workspaces such as studios, seminar rooms, offices from a particular perspective be seen as a superficial gesture, one that boils down to attaching a new name to the same old practice, in order to get hands on new funding? As the discussion progressed many obvious attractions in this particular name came up: It is connoting hard science, collective work processes and experimental approach - as well as a material hands-on-quality that agrees with the theoretical discourse of media archaeology. But it was also stressed, that there are in fact substantial qualities of the lab that go beyond the question of naming, qualities departing from the lab as a concrete space that 
could generate new energy and new types of knowledge production when transferred to the artistic and humanistic context.

The conversation made me think of the title of our conference A medium is a medium is a medium, a kick-start of the network Sensorium for young researchers working in the field between aesthetics, technology and materiality, as this title also addresses the question of what is in a name.

The title is a quote from Friedrich Kittler, who in Discourse Networks $1800 / 1900$ uses the sentence to stress the untranslatable quality of the medium: the important fact that any transfer from one medium to another involves a distortion - and thus the translation will always be to some degree arbitrary. But in Kittler the sentence is also a reminder about how the medium of language, as it is put to use in literature, has been considered as something close to an ideal channel - a channel of communication working without friction. By adding a third and final medium to his sentence, Kittler reminds us, essentially, that a medium is never just a channel or a technology of communication - it is always also something more. The material base makes a difference.

Even if Kittler does not give a reference, it is rather obvious that he is here paraphrasing Gertrude Stein's signature sentence "a rose is a rose is a rose is a rose" and as a Stein scholar I have not been able to refrain from a mild irritation that Kittler missed a part, he has only three times medium against Stein's four times rose.

Stein's sentence brings us back to the question of what's in a name. As has often been suggested, it addresses the famous passage from Romeo and Juliet, where Juliet is trying to disavow the importance of the name (due to the fact that her beloved Romeo is a Montague):

What's in a name.

that which we call A rose

by any other name would smell as sweet

As we all know, in the tragedy, the power of the name proves in- 
vincible and Juliet's pragmatic attitude does not help her much against the ruling discourse of the encompassing society breeding strife between her name and Romeo's. And even if Stein's sentence in the first instance may look like merely a very insistent statement that a rose, when all is said and done, is still a rose - just as Juliet claims - there is a lot more to say about it.

Stein herself said, among other things:

When I said.

A rose is a rose is a rose is a rose.

And then later made that into a ring I made poetry and what did I do I caressed completely caressed and addressed a noun.

("Poetry and Grammar," Lectures in America)

In another piece, Four In America, she claimed, that with this sentence, she made the rose red for the first time in English poetry in a hundred years. Knowing Stein, one shouldn't miss the homonymic play upon red - it is both the colour and the past tense of read. With Stein's sentence - the rose is both red and read for the first time.

What is particularly elegant in this embrace of Stein's of a noun, or of a name, is that in this very embracing movement she is calling the word's grammatical status into serious doubt. When the third part is added to "a rose is a rose" an unresolvable syntactical confusion is introduced - it becomes impossible to determine whether the second part is the end or the beginning of a clause - but as the forth part is introduced both the sounds and the grammar of language starts dissolving and transforms into genuine play. And every time the words "a rose", the article and the noun, are repeated and "caressed" they sound more like a verb - "arose". What seemed like an ultimate insistence upon the reality of a noun, is suddenly transformed into a verb - what appeared to be pure substance is turned into action.

Similarly current research in the fields of media history and media aesthetics - if we are to take the varied contributions made to this conference as representative - is concerned with regarding the medium as something more than an artefact: to 
take into account the essential materiality that, according to Kittler, is irreducible in any communication, but to also continuously understand the medium as something relational and entangled in dynamic processes. 